\title{
Adherence to Lifestyle Therapy in Patients with Chronic Heart Failure and Comorbidity
}

\author{
Elena Efremova ${ }^{1}$, Alexander Shutov ${ }^{1}$
}

\section{Department of Therapy and Professional Diseases, Institute of Medicine, Ecology and Physical Education, T.Z. Biktimirov Faculty of Medicine, Ulyanovsk State University, Ulyanovsk, Russia}

\author{
Corresponding author: \\ Associate Professor Elena Efremova \\ Department of Therapy and Professional Diseases, \\ Institute of Medicine, Ecology and Physical Education, \\ Ulyanovsk State University, Ulyanovsk, Russia \\ Email: Lena_1953@mail.ru
}

\begin{abstract}
\section{Background}

Influence of comorbidity on adherence to lifestyle therapy in patients with chronic heart failure (CHF) have not been studied yet.

The Aim

The aim of this study was to investigate awareness and adherence to lifestyle therapy in patientswith CHF and comorbidity.

Methods

203 patients with CHF ( 130 males and 73 females, mean age was $61.8 \pm 9.6$ years) were studied. CHF was defined according to ESC Guidelines for the diagnosis and treatment of acute and chronic heart failure, 2016. Age-adjusted Charlson comorbidity index was calculated. Awareness of lifestyle modifications was determined using a questionnaire developed in our clinic and used in previous scientific studies. Quality of life was estimated using SF-36 Health Status Survey. Psychological state and attitude to condition were estimated using MMPI, Personal Questionnaire of Behterevsk' Institute (LOBI), characterological questionnaire by K. Leonhard. Follow-Up period was 1 year.

Results

The awareness about lifestyle modifications in patients with CHF ranged from $38.9 \%$ (daily control of body weight) to $87.2 \%$ (limited salt intake). Adherence to lifestyle therapy was from $7.9 \%$ (daily weight control) to $37.9 \%$ (limited salt intake). Age-adjusted Charlson comorbidity index was 5.0 \pm 2.1 points. Patients with high comorbidity (Charlson comorbidity index $>6$ points) had decreased of quality of life, both in the physical and the psychological aspects. There were no differences in adherence to lifestyle therapy in patients with CHF, depending on comorbidity. Nonadherent patients were characterized by sensitive type of attitude to their condition, emotional lability, "exclusion" as a type of defence mechanism and negative coping strategies.
\end{abstract}

\section{Conclusions}

Nonadherence to lifestyle therapy in patients with CHF was associated with maladaptive type of attitude to their condition, which was more common in patients with high comorbidity.

Keywords: chronic heart failure; comorbidity; adherence to treatment; psychological status.

Citation: Efremova E, Shutov A. Adherence to lifestyle therapy in patients with chronic heart failure and comorbidity. International Cardiovascular Forum Journal. 2019;16:32-37. DOI: 10.17987/icfj.v16i0.574

\section{Introduction}

Chronic heart failure (CHF) is a major cause of mortality in the group of cardiovascular diseases in the world [1-2]. Low adherence to treatment is a widely extended problem among patients with CHF [3-4]. Besides medical treatment, lifestyle modifications improve the quality of life and prognosis of patients with cardiovascular diseases[5]. Non-drug treatment of CHF includes diet, self-care monitoring, exercise training, general recommendations for the regimen (stopping smoking, traveling, immunization etc.). Lifestyle modification strategy is individual for each patient and requires a multidisciplinary approach [6].According to the literature, failure to comply with recommendations for lifestyle changes in patients with $\mathrm{CHF}$ is associated with a poor prognosis. In studying the factors determining adherence to the treatment of CHF, traditionally emphasis has been given to social and pharmacoeconomic aspects [7]. At the same time, the influence of patients' personal characteristics, the behavioral and emotional spheres of the personality, has not been studied enough. licenses/by/4.0/), which permits use, distribution and reproduction, provided the original work is properly cited. Published by Barcaray (International) Publishing. 
Comorbidity is a feature of modern medicine. Comorbidity determines the emergence of new clinical and psychological symptoms and syndromes. The severity of the patient's condition is largely due to comorbidities and this problem fully applies to patients with CHF. [8].

This cohort prospective study demonstrates the influence of comorbidity on adherence to lifestyle therapy in patients with CHF.

\section{Methods \\ Study design}

Our research is a prospective cohort study with a 1 year follow up period. Disease outcomes (death, duration and frequency of hospitalization) were evaluated. The study protocol conforms to the ethical guidelines of the 1975 Declaration of Helsinki and was approved by the Ethical Committee of the Institute of Medicine, Ecology and Physical Education of Ulyanovsk State University. Informed consent was obtained from each patient.

\section{Inclusion criteria:}

- presence of CHF (according to ESC Guidelines for the diagnosis and treatment of acute and chronic heart failure, 2016) [9];

- signed informed consent

\section{Exclusion criteria:}

- acute myocardial infarction;

- acute cerebrovascular accident within 6 months prior to inclusion in the study;

- myocarditis;

- infective endocarditis;

- oncological diseases;

- severe cognitive impairment (moderate and severe dementia)

\section{Patient characteristics}

203 patients with CHF (130 males and 73 females, mean age was $61.8 \pm 9.6$ years), undergoing treatment at the Clinic cardiology department, were studied. CHF was defined according to ESC Guidelines for the diagnosis and treatment of acute and chronic heart failure, 2016.

The main causes of $\mathrm{CHF}$ were coronary artery disease and arterial hypertension. Causes of heart failure, clinical characteristics and comorbidity are presented in Table 1.177 patients (87.2\%) were living with family at the time of the examination; only $26(12.8 \%)$ patients were living alone. 85 (41.9\%) patients were working, 84 $(41.4 \%)$ patients had a disability.

\section{Comorbidity assessment}

The Charlson comorbidity index was calculated, including adjustment by age [10]. To calculate an age-adjusted Charlson comorbidity index, points (1 to 6) are summed for the presence of a particular condition (total of 19 conditions). Also, scores for age were calculated: 1 point (50-59), two points (60-69), 3 points (70-79 years), 4 points (80-89 years). The studied patients were divided into 3 groups: I group consisted of patients with an index of $\leq 3$ points (low comorbidity) - 53 patients; Group II consisted of patients with an index of 4-5 points (moderate comorbidity) 73 patients; Group III consisted of patients with an index of $\geq 6$ points (high comorbidity) - 77 patients.
Table 1. Clinical characteristics and comorbidity of patients with CHF

\begin{tabular}{|c|c|}
\hline Parameters & Abs (\%) \\
\hline \multicolumn{2}{|l|}{ Causes of heart failure } \\
\hline Coronary Artery Disease (CAD) & $9(4.4 \%)$ \\
\hline Arterial hypertension $(\mathrm{AH})$ & $24(11.8 \%)$ \\
\hline CAD with hypertension & $154(75.9 \%)$ \\
\hline Heart defects & $14(6.9 \%)$ \\
\hline Cardiomyopathy & $2(1 \%)$ \\
\hline \multicolumn{2}{|l|}{$\mathrm{CHF}$} \\
\hline NYHA class I & $18(8.9 \%)$ \\
\hline NYHA class II & $109(53.7 \%)$ \\
\hline NYHA class III & 77 (37.9\%) \\
\hline NYHA class IV & $2(1 \%)$ \\
\hline 6-minute walk test, $\mathrm{m}$ & $327.0+84.9$ \\
\hline Duration of $\mathrm{CHF}$, years & $4.3 \pm 1.8$ \\
\hline \multicolumn{2}{|l|}{ Comorbidity } \\
\hline Arterial hypertension & $191(94.1 \%)$ \\
\hline Coronary artery disease, including & $163(80.3 \%)$ \\
\hline myocardial infarction & $46(22.7 \%)$ \\
\hline Arrhythmias, & $57(28.1 \%)$ \\
\hline including permanent atrial fibrillation & $30(14.8 \%)$ \\
\hline $\begin{array}{l}\text { Chronic kidney disease (GFR }<60 \mathrm{ml} / \mathrm{min} / \\
1.73 \mathrm{~m} 2 \text { ) }\end{array}$ & $89(43.8 \%)$ \\
\hline Dementia & $46(22.7 \%)$ \\
\hline Type 2 diabetes, including & $34(16.7 \%)$ \\
\hline with lesions of target organs & $15(7.4 \%)$ \\
\hline $\begin{array}{l}\text { Obliterating atherosclerosis of the lower } \\
\text { extremities }\end{array}$ & $25(12.3 \%)$ \\
\hline Stomach ulcer & $24(11.8 \%)$ \\
\hline Acute ischemic stroke in history, & $22(10.8 \%)$ \\
\hline including developmental hemiplegia & $1(0.5 \%)$ \\
\hline Chronic nonspecific lung diseases & $21(10.3 \%)$ \\
\hline Connective tissue diseases & $21(10.3 \%)$ \\
\hline $\begin{array}{l}\text { Moderate liver disease } \\
\text { (viral hepatitis in history) }\end{array}$ & $7(3.4 \%)$ \\
\hline Malignant tumors without metastasis & $6(2.9 \%)$ \\
\hline \multicolumn{2}{|c|}{$\begin{array}{l}\text { Legend to table } 1 \\
\mathrm{CAD}=\text { Coronary Artery Disease } \\
\mathrm{AH}=\text { Arterial Hypertension } \\
\mathrm{CHF}=\text { Chronic Heart Failure } \\
\text { NYHA = New York Heart Association Functional Classification }\end{array}$} \\
\hline
\end{tabular}

\section{Adherence assessment}

Awareness of lifestyle modifications was determined using a questionnaire developed in our clinic that has been used previously in published studies [4]. Patients were asked questions clarifying the need for daily monitoring of body weight, restrictions on salt, regular physical activity. The response options were given as "yes", "no", "I do not know". For a more detailed analysis of patients' adherence to the lifestyle modifications, the questionnaire included the following questions: "Do you have scales at home?", "How often do you monitor your weight?"; "Do you limit salt intake?", "To what extent do you limit salt intake?"; "How often do you do physical exercises?"; "What is the duration 
of training?"; "Is there daytime sleep in your daily routine?", "Do you smoke?"; "Do you take alcohol?". In addition, the information regarding immunization against influenza (annually), hepatitis $B$, periods of long flights and the presence of a self-control diary was included in the questionnaire. Adherence to lifestyle therapy was considered satisfactory when patients performed at least $80 \%$ of the recommendations[11].

\section{Quality of life and psychological state assessment}

The Mini-Mental State Examination (MMSE) was used to assess the cognitive functions of patients with CHF. Quality of life was estimated using 36-item short-form health survey (SF-36). [12]. Validated psychological methods were used to study the personality characteristics of patients with CHF. Psychological state estimated using Minnesota Multiphasic Personality Inventory (MMPI), attitude to disease - Personal Questionnaire of Behterevsk' Institute (LOBI), types of character accentuation characterological questionnaire K. Leonhard.

\section{Statistical analysis}

Statistical analysis was performed using the computer package Statistica for Windows 8.0. Depending on the type of distribution, the data was presented as the $M \pm S D$ (where $M$ is the arithmetic average; SD is the standard deviation, or as the median and 95\% confidence interval $(95 \% \mathrm{Cl})$. ANOVA test, the Kruskal-Wallis method was used for the comparison of the groups. The significance of differences between the parameters was determined using Student's parametric t-test for unpaired variables and the Mann-Whitney non-parametric test; $x 2$ was calculated for categorical variables. A one-factor correlation analysis was carried out according to Pearson or the Spearman for non-parametric distribution. Multivariate regression analysis was used. A p-value $<0.05$ was considered statistically significant.

\section{Comorbidity in patients with CHF}

The age-adjusted Charlson comorbidity index was $5.0 \pm 2.1$ points. The average number of diseases per patient was $4.6 \pm 1.6$ ( 1 to 10 nosological forms). Patients with CHF with high comorbidity were older than patients with low comorbidity: $67.6 \pm 8.2$ and $55.2 \pm 7.0$ years, respectively, pllI-I $<0.0001$. The total number of nosological forms in patients with CHF also increased with age $(r=0.25, p=$ $0.005)$. The age-adjusted Charlson comorbidity index was $4.9 \pm 2.1$ points for men and 5.1 \pm 2.2 points for women $(p=0.78)$.

Chronic kidney disease (CKD) was the most frequent component in the structure of comorbidity of patients with CHF (89; 43.8\%). However, if we excluded CKD from the age-adjusted Charlson comorbidity index, patients with chronic cardiorenal syndrome had a higher comorbidity $(4.3 \pm 1.8$ vs $3.8 \pm 1.7$ points, resp., $p=0.01$ ).

Patients with high comorbidity had a higher NYHA class $(2.8 \pm 0.5$ and $2.0 \pm 0.6$, respectively, plll- $\mathrm{I}<0.0001)$. The level of comorbidity increased with the duration of $\mathrm{CHF}(r=0.28, p<0.0001)$.

\section{Awareness of lifestyle modifications}

77 (37.9\%) patients with CHF regularly ("always") limited salt intake to $6 \mathrm{~g}$ /day. 16 (7.9\%) patients with CHF monitored their weight regularly ("daily"). More than half of patients (121; 59.6\%) had scales at home. $53(26.1 \%)$ patients performed regular physical exercise ("more than 4 times a week"). The main types of physical activity of patients with CHF were walking - 49 (22.7\%) and morning exercises - 31 (15.3\%). 10 (4.9\%) patients were engaged in seasonal sports (skiing, cycling, volleyball), 8 (3.9\%) patients with CHF swam at a pool (Figure 1). The duration of training in most cases (65\%) was 30 minutes.

41 (20.2\%) patients with CHF were vaccinated for hepatitis B. 66 (32.5\%) patients with CHF were annually vaccinated against influenza. Patients with CHF who were not vaccinated had a higher Charlson comorbidity index: $5.2 \pm 2.2$ and $4.2 \pm 1.9$ points, respectively, $p=0.006$.

There were 42 (20.7\%) smoking patients with CHF, all were males. Smokers were 42 (20.7\%) patients with CHF only among males. 39 (19.2\%) patients stopped smoking, but they were smokers in the past, $122(60.1 \%)$ patients never smoked. Smoking patients had a higher Age-adjusted Charlson comorbidity index than nonsmoking patients: $5.2 \pm 2.2$ and $4.3 \pm 2.9$, resp., $p=0.02$. Smoking patients had excitable types of character accentuation ( $r=$ $0.25 ; p=0.03$ ), which indicated irritability, demandingness, and increased conflict. The majority of patients $(167 ; 82.3 \%)$ drunk alcohol at least 1 time per month. None of the patients consumed alcohol daily, 36 (17.7\%) patients with CHF consumed alcohol 1-3 times a week.

33 (16.3\%) patients with CHF were keeping self-monitoring diaries. The majority of patients with $\mathrm{CHF}$ and arterial hypertension and 182 (89.7\%) had apparatus for measuring blood pressure. However, only 96 (47.2\%) patients with CHF and arterial hypertension monitored the blood pressure daily as per their doctor's recommendation.

Only $37(18.2 \%)$ patients were fully adherent to lifestyle therapy as a result. There were no statistically significant differences in adherence to lifestyle therapy in patients with CHF, depending on the level of comorbidity.

The awareness about lifestyle modifications in patients with CHF ranged from $38.9 \%$ (daily control of body weight) to $87.2 \%$ (excessive salt intake). Only half of the patients, who knew about lifestyle modifications, followed medical advice. The ratio of the awareness about lifestyle modifications and adherence to lifestyle modifications is presented in Figure 2.

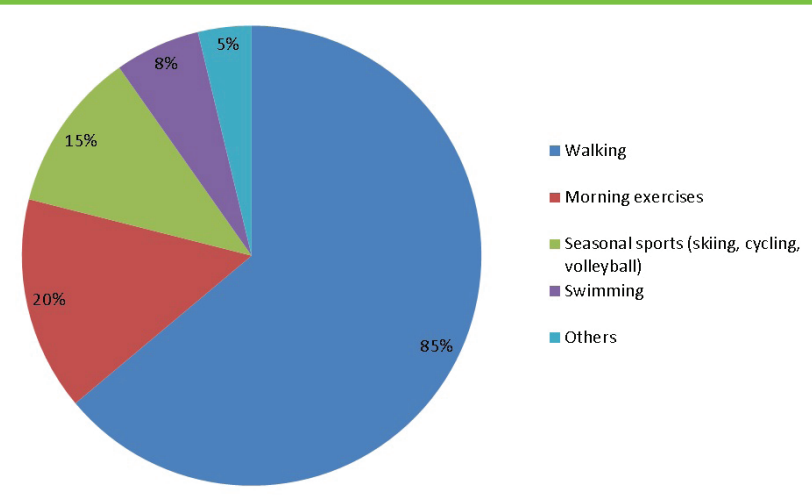

Figure 1

Types of physical activity of patients with $\mathrm{CHF}$ $\mathrm{CHF}=$ Chronic Heart Failure 


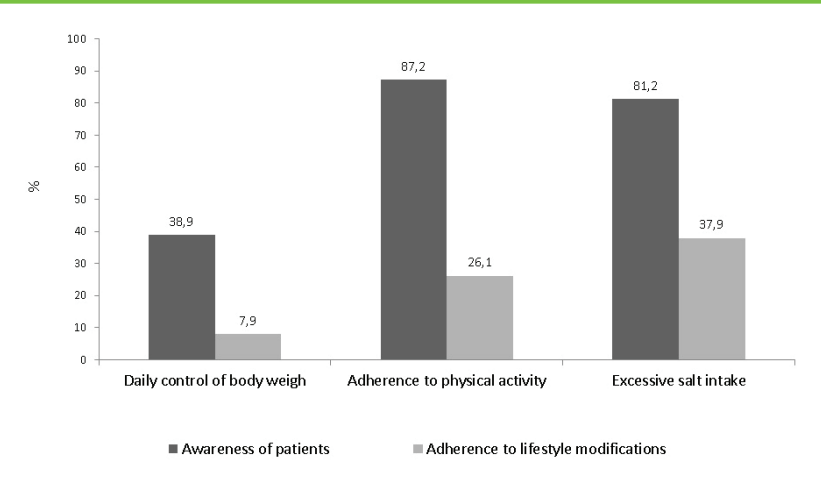

Figure 2

The ratio of the awareness about lifestyle modifications and adherence to lifestyle modifications

\section{Quality of life and psychological state}

Patients with high comorbidity (Age-adjusted Charlson comorbidity index $>6$ points) had a decreased quality of life, both in the physical and the psychological aspects (Fig.3).

Patients with CHF, engaging in physical activity, had higher quality of life indicators according to the scales of the physical component of health: physical functioning $(r=0.30, p=0.003)$ and physical role functioning $(r=0.31 ; p=0.001)$; and on the scale of the psychological component of health: emotional role function $(r=0.30, p=0.002)$.

According to the results of multivariate diagnostics (MMPI), significant differences were observed between the averaged profiles of patients with high, moderate and low comorbidity (Fig.4)

In the MMPI profile patients with comorbidity had higher T-scores on the scales of depression (D) $(63.2 \pm 14.4$ and $57.7 \pm 14.5 \mathrm{~T}$-scores, respectively, $\mathrm{pW-II}=0.01 ; 63.2 \pm 14.4$ and $53.9 \pm 13.9 \mathrm{~T}$-scores, respectively, $\mathrm{pW-} \mid<0.0001)$, schizophrenia (Sc) $(66.9 \pm 9.1$ and $61.2 \pm 10.7$ T-scores, respectiely, pIII-II $=0.0001 ; 66.9 \pm 9.1$ and $59.6 \pm 11.7$ T-scores, respectively, $\mathrm{pW}-\mathrm{I}=0.001)$, psychasthenia (Pt) $(68.8 \pm 9.4$ and $62.4 \pm 10.5$ T-scores, respectively, pШ$\mathrm{II}=0.0001 ; 68.8 \pm 9.4$ and $61.9 \pm 12.4$ T-scores, respectively $p$ Ш-I=0,0004) with a maximum rise on the hypochondriasis (Hs) $(78.3 \pm 5.3$ and $72.9 \pm 13.1 \mathrm{~T}$-scores, resp., p Ш-II =0.02; $78.3 \pm 15.3$ and $72.7 \pm 10.6$ T-scores, respectively, $\mathrm{pW-I}=0,02$ ). These code types indicated the prevalence of mixed type of response in patients with CHF with high comorbidity, as well as significant emotional discomfort, passive attitude and difficulty of adaptation.

The sensitive (38.4\%), paranoid (36.9\%), neurotic (27.8\%) types of attitude towards their disease dominated in the internal structure of the disease independent on comorbidity. Combinations of these types of attitude demonstrated impaired social adaptation/social adjustment processes of patients with CHF. Patients with high comorbidity, as compared to patients with low comorbidity, often observed maladaptive phobic obsessive type attitude towards their conditions (4 (9.4\%) and $16(20.7 \%)$, respectively, X2 $=4.22$; pIII-I = 0.04). This was expressed in suspiciousness about the improbable complications of the disease and treatment failure.

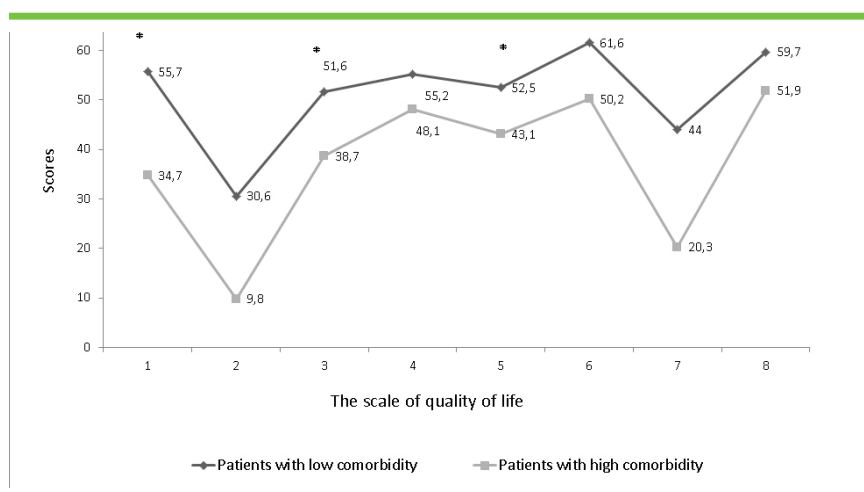

Figure 3

Profile of the quality of life in patients with $\mathrm{CHF}$, depending on comorbidity

$\mathrm{CHF}=$ Chronic Heart Failure

Note: 1 - physical functioning, 2 - physical role functioning, 3 - pain, 4 - general health, 5 - energy, 6 - social functioning, 7 - emotional role functioning, 8 - emotional well-being. * $-\mathrm{P}<0.01$.

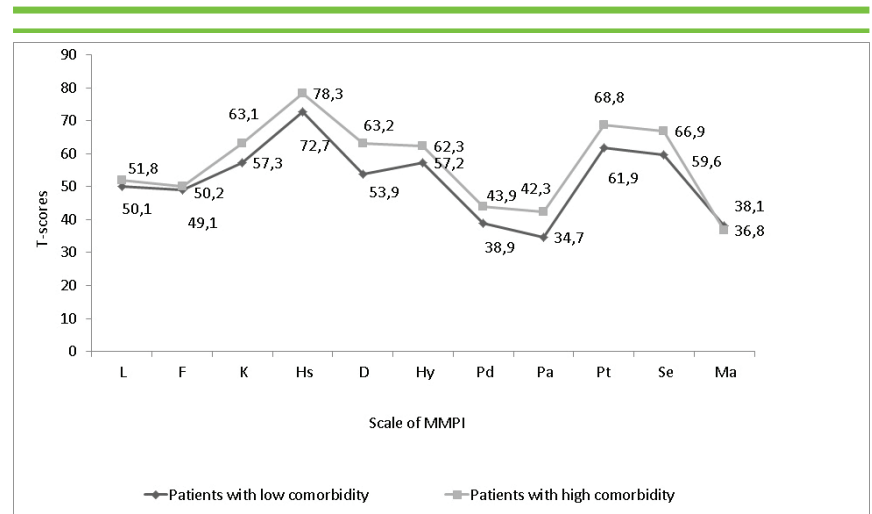

Figure 4

Profile of MMPI in patients with CHF, depending on comorbidity. $\mathrm{CHF}=$ Chronic Heart Failure

$\mathrm{MMPI}=$ Minnesota Multiphasic Personality Inventory

Note:

Scale: L - lies, F - reliability, K - correction, Hs - hypochondriasis, D - depression, Hy - hysteria, Pd - psychopathic deviate, $\mathrm{Pa}$ - paranoia, Pt - psychasthenia, Sc - schizophrenia, Ma hypomania

The emotive type of character accentuation (13.6 \pm 6.4 points) was dominant in patients with CHF. Moreover, in patients with low comorbidity, the intensity of the emotive type accentuation was greater than in patients with high comorbidity $(15.3 \pm 5.5$ and $12.0 \pm 7.1$ points, respectively, pl-III $=0.03)$, which indicated hypersensitivity, impressionability, lack of motivation and mood variability.

There were personal characteristics of patients with $\mathrm{CHF}$ associated with comorbidity and adherence to lifestyle therapy. Good adherence was associated with the emotive type of character accentuation $(p<0.001)$. Non-adherent patients were characterized by sensitive type of attitude towards their disease, emotional lability, "exclusion" as a type of defence mechanism, negative coping strategies $(p<0.05)$.

\section{Discussion}

Patients with CHF have high comorbidity. $74 \%$ of patients with $\mathrm{CHF}$ had at least one concomitant medical condition, according to the European Study (European Heart Failure Pilot Survey). The 
most common condition in the group of comorbidity are CKD (41\%), anemia (29\%) and diabetes (29\%) [13-14]. We obtained similar results in our study. According to the results of our study, in $74 \%$ of patients with CHF had Age-adjusted Charlson comorbidity index 4 points or more. CKD was the most common pathology (44\%). Comorbidity was independently associated with older age and higher NYHA class of CHF [14].

Comorbidity is associated with a decrease in quality of life and an increase in the number of anxiety and depressive disorders in patients with chronic diseases [15]. In our study, the profile of quality of life in patients with CHF and high comorbidity was significantly lower on all scales than in patients with low comorbidity. The hypochondriasis in patients with $\mathrm{CHF}$ and comorbidity also reduced the quality of life.

Two major studies COMPASS and HF-ACTION showed that the symptoms of depression and anxiety were present in approximately half of patients with hypertension, coronary artery disease and heart failure. It affected almost every third patient: patients with hypertension $-28 \%$, with coronary artery disease - 31\%, with CHF - 38\% [16, 17]. Depression negatively affects adherence to treatment in patients with $\mathrm{CHF}$ [18].

In the course of treatment, both emotional and motivational areas of the patient with $\mathrm{CHF}$ are reorganized, which can also lead to the disruption of social adaptation. In our study of motivational aspect of patients with CHF demonstrated uniform adaptation processes depending on comorbidity.

According to multidimensional diagnosis of personal characteristics of patients with CHF and high comorbidity had a hypochondriac personal profile, high scores on the "disability" scale, which indicates emotional tension, self-centeredness, pronounced impulsivity, passive attitude to the conflict, avoiding problem solving, consumer attitude to one's illness, suspicion and disbelief in the effectiveness of the treatment.

Patients with CHF avoid excessive salt intake ( $>6 \mathrm{~g} /$ day) [9]. In some studies more severe restriction of sodium intake $<2.5 \mathrm{~g} /$ day, resulted in a negative haemodynamic and neurohumoral changes, as well as an increase in the number of hospitalizations and the risk of death. Limiting salt intake correlates with the severity of symptoms of the disease and the presence of stagnation in patients with CHF [19]. Given the national characteristics of salt intake (up to $10.8 \mathrm{~g} /$ day) patients should be given information about reasonable levels of salt intake according to WHO' recommendation (5-6 g/day) [20]. According to the literature, a low salt diet is regularly observed in 50 to $80 \%$ of patients with CHF [21]. In general, according to the results of the study, 77 (37.9\%) patients with CHF regularly ("always") limited salt intake.

According to European and Russian recommendations, Patients with $\mathrm{CHF}$ are recommended to be weighed daily and writing the results in a diary $[8,22]$. Patients with CHF with sufficient awareness regularly monitor their weight from 12 to $75 \%$ [23]. In our study only 21 (10.3\%) patients with CHF were informed about the need for medical consultation with an increase in weight of 2-3 kg per 1-2 days.
Physical activity is mandatory in patients with CHF. Aerobic physical training of moderate intensity in patients with $\mathrm{CHF}$ contributes to the improvement of NYHA class and leads to an improvement of quality of life and decreased hospitalizations. Aerobic workouts are preferred, while training in the water does not have sufficient evidence [24]. Regular physical activity reduces overall and cardiovascular mortality by more than $30 \%$, and also improves the psycho-emotional state [25]. In our research, only every fifth patient with $\mathrm{CHF}$ had regular exercise, mainly aerobic, which improved patients' quality of life.

Patients with CHF are recommended to quit smoking and reduce alcohol consumption. In our study, every fifth patient smoked and was not abusing alcohol. These results are possible due to the patient's insincerity during the interview.

Satisfactory adherence to lifestyle change recommendations was observed only in 37 (18.2\%) patients with CHF, despite sufficient awareness of lifestyle changes. Our results correlate with other studies in which knowledge of the necessary changes in lifestyle was not sufficient to form a satisfactory adherence to non-drug treatment [26]. There were no differences in adherence to nondrug therapy in patients with CHF, depending on comorbidity. However, the personality characteristics of patients with CHF and comorbidity, determine the presence of a satisfactory adherence to lifestyle change recommendations of patients with $\mathrm{CHF}$.

The data collected in this research reflects actual clinical practice. As a recommendations for clinical practice, a comprehensive examination of patients with CHF should include Age-adjusted Charlson comorbidity index to clarify the prognosis of patients with $\mathrm{CHF}$ and the degree of adherence to therapy.

In order to identify predictors of satisfactory adherence to treatment in patients with $\mathrm{CHF}$, it is recommended to use the following psychodiagnostic methods: Minnesota Multiphasic Personality Inventory (MMPI), Personal Questionnaire of Behterevsk' Institute (LOBI) and characterological questionnaire by K. Leonhard. Patients with an obsessive-phobic type of attitude to disease (which is detected when using the LOBI; high rates on the MMPI scales "psychasthenia" and "schizophrenia"), are characterized by unsatisfactory adherence to treatment and need constant monitoring and an individual approach aimed at increasing adherence to treatment.

The scientific data obtained from the study, fits the modern concept of a multidisciplinary approach to the treatment of patients with $\mathrm{CHF}$.

\section{Limitations}

Our study had a number of limitations, including research sample limitations, short observation period, data collection methodology, inability to assess whether patients were honest.

\section{Conclusion}

Only every fifth patient with CHF was adherent to lifestyle therapy despite the level of awareness about lifestyle modifications and comorbidity. Comorbidity decreased the quality of life of patients with $\mathrm{CHF}$ on physical and mental health components. Comorbidity was associated with the maladaptive type of attitude towards disease, hypochondriasis and depression. Poor 
adherence to lifestyle modifications was largely due to personal characteristics of patients with CHF. Nonadherence to lifestyle therapy in patients with CHF was associated with maladaptive type of attitude towards disease, which was more common in patients with high comorbidity.

\section{Declarations of Interest}

The authors declare no conflicts of interest.

\section{Acknowledgements}

The authors agree to abide by the requirements of the "Statement of publishing ethics of the International Cardiovasular Forum Journal” [27].

\section{References}

1. Metra M, Ponikowski P, Dickstein K, McMurray JJ V, Gavazzi A, Bergh C-H, Fraser AG, Jaarsma T, Pitsis A, Mohacsi P, Bo"hm M, Anker S, Dargie $H$, Brutsaert D, Komajda M. Advanced chronic heart failure: a position statement from the Study Group on Advanced Heart Failure of the Heart Failure Association of the European Society of Cardiology. Eur J Heart Fail. 2007; 9(6-7):684-94, DOI: 10.1016/j.ejheart.2007.04.003

2. Mosterd A, Hoes AW. Clinical epidemiology of heart failure. Heart. 2007; 93(9):1137-46, DOI: 10.1136/hrt.2003.025270

3. Wolfel EE. Can we predict and prevent the onset of acute decompensated $\begin{array}{lll}\text { heart failure? Circulation. 2007;116 (14):1526-9, DOI:10.1161/ } & \end{array}$ CIRCULATIONAHA. 107.729608

4. Efremova EV, Shutov AM, Borodulina EO. Treatment motivation in patients with chronic cardiorenal syndrome. Ter Arkh. 2015;87(12):13-17, DOI: 10.17116/terarkh2015871213-17. (In Russ.)

5. van der Wal MHL, van Veldhuisen DJ, Veeger NJGM, Rutten FH, Jaarsma $\mathrm{T}$. Compliance with non-pharmacological recommendations and outcome in heart failure patients. Eur Heart J. 2010;31 (12):1486-93, DOI:10.1093/ eurheartj/ehq091

6. Lainscak M, Blue L, Clark AL, Dahlstro"m U, Dickstein K, Ekman I, McDonagh T, McMurray JJ, Ryder M, Stewart S, Stro"mberg A, Jaarsma T. Self-care management of heart failure: practical recommendations from the Patient Care Committee of the Heart Failure Association of the European Society of Cardiology. Eur J Heart Fail. 2011;13(2):115-26, DOI: 10.1093/ eurjhf/hfq219

7. Russell CL, Ruppar TM, Matteson M. Improving medication adherence: moving from intention and motivation to a personal systems approach. Nurs Clin North Am. 2011 Sep;46(3):271-81, DOI: 10.1016/j.cnur.2011.05.004

8. Kernick D, Chew-Graham CA, O'Flynn N. Clinical assessment and management of multimorbidity: NICE guideline. $\mathrm{Br} \mathrm{J}$ Gen Pract. 2017; 67(658): 235-56, DOI: 10.3399/bjgp17X690857

9. Ponikowski P, Voors AA, Anker SD, Bueno H, Cleland JG, Coats AJ, Falk V, González-Juanatey JR, Harjola VP, Jankowska EA, Jessup M, Linde C, Nihoyannopoulos P, Parissis JT, Pieske B, Riley JP, Rosano GM, Ruilope LM, Ruschitzka F, Rutten FH, van der Meer P; 2016 ESC Guidelines for the diagnosis and treatment of acute and chronic heart failure: The Task Force for the diagnosis and treatment of acute and chronic heart failure of the European Society of Cardiology (ESC). Developed with the special contribution of the Heart Failure Association (HFA) of the ESC. Eur J Heart Fail. 2016 Aug;18(8):891-975, DOI: 10.1002/ejhf.592

10. Charlson ME, Pompei P, Ales KL, MacKenzie CR. A new method of classifying prognostic comorbidity in longitudinal studies: development and validation. J Chron Dis. 1987; 40(5):373-83

11. World Health Organization. Preventing chronic diseases: a vital investment. Geneva: WHO, 2005. p.182, ISBN 9241563001

12. Ware JE Jr, Sherbourne CD. The MOS 36 -item short-form health survey (SF-36). I. Conceptual framework and item selection. Med Care. 1992; 30(6):473-83

13. Dickson VV, Buck H, Riegel B. A qualitative meta-analysis of heart failure self-care practices among individuals with multiple comorbid conditions. J Card Fail. 2011;17(5):413-9, DOI: 10.1016/j.cardfail.2010.11.011

14. Van Deursen VM, Urso R, Laroche C, Damman K, Dahlström U, Tavazzi L, Maggioni AP, Voors AA. Co-morbidities in patients with heart failure: an analysis of the European Heart Failure Pilot Survey. Eur J Heart Fail. 2014;16(1):103-11, DOI: 10.1002/ejhf.30

15. Dickson VV, Buck H, Riegel B. A qualitative meta-analysis of heart failure self-care practices among individuals with multiple comorbid conditions. J Card Fail. 2011;17 (5):413-9, DOI: 10.1016/j.cardfail.2010.11.011

16. Oganov R.G., Pogosova G.V., Shalnova S.A., Deev A.D. Depressive disorders in general medical practice according to the KOMPAS study: a view of a cardiologist. Cardiology. 2005;(8):37-43, DOI: 10.12731/wsd2017-1-10-28 (In Russ.)

17. Gottlieb SS, Kop WJ, Ellis SJ, Binkley P, Howlett J, O'Connor C, Blumenthal JA, Fletcher G, Swank AM, Cooper L; HF-ACTION Investigators. Relation of depression to severity of illness in heart failure (from Heart Failure And a Controlled Trial Investigating Outcomes of Exercise Training [HFACTION]). Am J Cardiol. 2009; 103:1285-9, DOI: 10.1016/j.amjcard.2009.01.025

18. DiMatteo MR, Lepper HS, Croghan TW Depression Is a Risk Factor for Noncompliance With Medical Treatment: Metaanalysis of the Effects of Anxiety and Depression on Patient Adherence. Arch Intern Med. 2000; 160(14):2101-7, DOI:10.1001/archinte. 160.14.2101

19. Lainscak M, Blue L, Clark AL, Dahlström U, Dickstein K, Ekman I, McDonagh T, McMurray JJ, Ryder M, Stewart S, Strömberg A, Jaarsma T. Self-care management of heart failure: practical recommendations from the Patient Care Committee of the Heart Failure Association of the European Society of Cardiology. Eur J Heart Fail. 2011;13(2):115-26, DOI:10.1093/ eurjhf/hfq219

20. Doukky R, Avery E, Mangla A, Collado FM, Ibrahim Z, Poulin MF, Richardson D, Powell LH. Impact of Dietary Sodium Restriction on Heart Failure Outcomes. JACC: Heart Failure. 2016;4 (1):24-35, DOI:10.1016/j. jchf. 2015.08.007

21. Carlson B., Riegel B., Moser D.K. Self-care abilities of patients with heart failure. Heart Lung. 2001;30(5):351-9, DOI: 10.1067/mhl.2001.118611

22. Mareev VYu, Fomin IV, Ageev FT, Begrambekova YuL, Vasyuk YuA, Garganeeva AA, Gendlin GE, Glezer MG, Gautier SV, Dovzhenko TV, Kobalava ZhD, Koziolova NA, Koroteev AV, Mareev YuV, Ovchinnikov AG, Perepech NB, Tarlovskaya El, Chesnikova Al, Shevchenko AO, Arutyunov GP, Belenkov YuN, Galyavich AS, Gilyarevsky SR, Drapkina OM, Duplyakov DV, Lopatin YuM, Sitnikova MYu, Skibitsky VV, Shlyakhto EV. Russian Heart Failure Society, Russian Society of Cardiology. Russian Scientific Medical Society of Internal Medicine Guidelines for Heart failure: chronic (CHF) and acute decompensated (ADHF). Diagnosis, prevention and treatment. Cardiology. 2018; 58 (S6), DOI: 10.18087/cardio. 2475. (In Russ.)

23. van der Wal MH, Jaarsma T, Moser DK, Veeger NJ, van Gilst WH, van Veldhuisen DJ. Compliance in heart failure patients: the importance of knowledge and beliefs. Eur Heart J. 2006;27(4):434-40, DOI: 10.1093/ eurheartj/ehi603

24. Shah P, Pellicori P, Macnamara A, Urbinati A, Clark AL. Is Swimming Safe in Heart Failure? A Systematic Review. Cardiol Rev. 2017;25(6):321-5, DOI: 10.1097/CRD. 0000000000000154

25. Nocon M, Hiemann T, Müller-Riemenschneider F, Thalau F, Roll S, Willich SN Association of physical activity with all-cause and cardiovascular mortality: a systematic review and meta-analysis. Eur J Cardiovasc Prev Rehabil. 2008;15(3):239-46, DOI: 10.1097/HJR.0b013e3282f55e09

26. Holzapfel N, Löwe B, Wild B, Schellberg D, Zugck C, Remppis A, Katus HA, Haass M, Rauch B, Jünger J, Herzog W, Müller-Tasch T Selfcare and depression in patients with chronic heart failure. Heart Lung. 2009;38(5):392-7, DOI: 10.1016/j.hrtlng.2008.11.001

27. Shewan LG, Coats AJS, Henein MY. Authors' Responsibilities and Ethical Publishing. International Cardiovascular Forum Journal 2018;13:3-4, DOI: $10.17987 /$ icfj.v13i0.525 